\title{
CONSIDERAÇÕES SOBRE O FUNDAMENTO MORAL DA PROPRIEDADE
}

\author{
Luiz Felipe Netto de Andrade e Silva Sahd* \\ felipesahd@yahoo.com.br
}

\begin{abstract}
RESUMO Para Hugo Grotius a propriedade era originalmente coletiva, e os homens tinham, de comum acordo, decidido dividi-la, o que havia feito nascer a propriedade privada. Como a propriedade privada devia ser garantida pelo governo, ela só podia ser uma emanação deste. O problema dessa análise, para John Locke, era que ela era perfeitamente compativel com o absolutismo, pois um monarca podia garantir essa propriedade. Como Locke funda a propriedade sobre a lei natural, sua teoria da prioridade refuta, ao mesmo tempo, as teorias de Sir Robert Filmer e de Grotius e Samuel Pufendorf. A teoria da propriedade de Locke garante, por fim, a liberdade dos indivíduos.
\end{abstract}

Palavras-Chave Propriedade Privada; Lei Natural; Soberania; Contrato; Liberdade; Absolutismo

\begin{abstract}
According to Hugo Grotius, property was originally collective, and men had commonly agreed to divide it. Consequence: private property. And private property should be guaranteed by the government, therefore, it had to emanate from it. To John Locke, the problem of such an analysis is that it is perfectly compatible with Absolutism, since the king could guarantee, in these terms, property as well. John Locke founds property on natural law, and doing so, refutes simultaneously Samuel Pufendorf's, Hugo
\end{abstract}

* Professor da Universidade Federal de Uberlândia - UFU. Artigo recebido em outubro de 2006 e aprovado em abril de 2007.

KRITERION, Belo Horizonte, nº 115, Jun/2007, p. 219-234. 
Grotius' and Robert Filmer's theories about the same subject. John Locke's theory of property guarantees individual freedom.

Keywords Private Property; Natural Law; Sovereignty; Contract; Freedom; Absolutism

Ao estudar a crítica de John Locke ao Patriarcha de Sir Robert Filmer, apanhamos o essencial da argumentação lockeana sobre os fundamentos morais da propriedade. Nas páginas do Primeiro Tratado sobre o Governo, Locke demonstra que a doação do mundo, contida no Gênesis I, 28-29, foi realizada em benefício de toda a humanidade. A descrição da propriedade originária supõe a sua definição como um direito em comum que pertence a todos os membros da espécie humana: "O que quer que Deus tenha outorgado através das palavras dessa concessão $(\mathrm{Gn} 1,28)$, não o outorgou para Adão em particular, à exclusão de todos os demais homens: qualquer que tenha sido o domínio que lhe outorgou mediante tal concessão, não se tratava de um domínio privado, mas um domínio em comum com o restante da humanidade."1 Com essa manobra, Locke destruiu a imagem monárquica e autoritária que descrevia o mundo como um domínio privado de Adão e seus herdeiros, e a substituiu por outra igualitária que a mostrava, nas palavras de John Dunn, "como pertencente a ninguém, mas disponível a apropriação de todos". ${ }^{2}$

Mas qual é o traço característico dessa propriedade em comum de que fala Locke? Como sustenta James Tully, essa propriedade original é um direito que todos os homens possuíam: um direito de uso exclusivo; um direito a algo que pertence a todos e está subordinado ao cumprimento de uma finalidade concreta: a sobrevivência e o bem-estar de cada homem e de toda a espécie humana. ${ }^{3}$ Mais exatamente, essa propriedade comum que desfruta a humanidade está destinada de antemão a facilitar o cumprimento do dever de perpetuação e bem-estar dos homens. John Locke diz: 
(...) Deus, que determinou à humanidade crescer e multiplicar-se, teria, antes, concedido a todos um direito de fazer uso do alimento, do vestuário e outras comodidades da vida de cujos materiais ele os proveu com tal abundância. ${ }^{4}$

A idéia que fundamenta a descrição de Locke do domínio originário da humanidade é simples, ela remete à temática tradicional da communitas rerum ou dominium tomista: um domínio em comum que os homens desfrutavam sobre o mundo e que era contraposto a possidere comuniter ou proprietas, remetente àquela esfera dominical que permitia a cada homem fazer uso das coisas para seu benefício particular. Mas essa comunidade originária foi redefinida por Locke sob a perspectiva da concepção subjetiva dos direitos que paulatinamente se desenvolveram a partir do Renascimento. Nesse sentido, a doação originária na qual falava Locke se configura como um direito em comum sobre as coisas do mundo. Um direito que é descrito em termos muito parecidos aos que Francisco Suárez apresenta em seu De legibus ac Deo legislatore (1612), quando distingue entre um ius ad rem e um ius in re, isto é, entre um poder moral para adquirir uma coisa que, todavia, não é possuída efetivamente (ius ad rem) e um poder sobre o que se adquiriu e já está sendo usufruído (ius in re). ${ }^{5}$

Na realidade, a doação do mundo que Deus fez aos homens atribuiu-lhes uma espécie de ius ad rem a cada um deles. ${ }^{6}$ Para utilizar a expressão forjada por Crawford Brough Macpherson, essa propriedade comum que desfrutava a espécie humana era um direito inclusivo (inclusive right): um direito que atribuía a seu titular o poder de exigir aos outros que não fora excluído do uso das coisas do mundo ou, para dizer de outro modo, um poder que permitia reclamar a inclusão nesse mesmo uso que compartilhavam todos os homens. ${ }^{7}$ Desse modo, cada membro da espécie humana desfrutava de um ius ad rem sobre o mundo: um poder moral para adquirir as coisas que necessitava para sobreviver.

Uma vez que Locke prova que essa comunidade primitiva que desfrutava a humanidade foi desejada pelas Escrituras e era plenamente coerente com a razão, o passo seguinte foi demonstrar, através de uma teorização baseada na lei natural, como podia ser exercido esse direito inclusivo ou ius ad rem, e quais eram os mecanismos que o transformaram num direito exclusivo ou

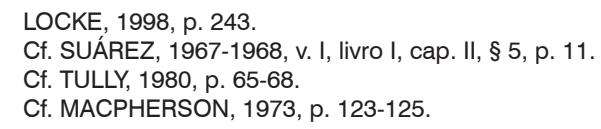


ius in re. Eis o que escreve o autor no início do capítulo quinto do Segundo Tratado sobre o Governo:

Quer consideremos a razão natural - que nos diz que os homens, uma vez nascidos, têm direito à sua preservação e, portanto, à comida, bebida e a tudo quanto a natureza lhes fornece para sua subsistência - ou a revelação - que nos relata as concepções que Deus fez do mundo para Adão, Noé e seus filhos -, é perfeitamente claro que Deus, como diz o rei Davi (S1 115, 61), deu a terra aos filhos dos homens, deu-a para a humanidade em comum. ${ }^{8}$

À tarefa de explicar como se transforma o ius ad rem originário em um ius in re, dedica precisamente o capítulo quinto do Segundo Tratado, tal como o próprio Locke reconhece, não sem antes admitir que "parece ser da maior dificuldade, para alguns, entender como pode alguém chegar a ter a propriedade de alguma coisa". De qualquer maneira, Locke admite expressamente que o seu propósito será o de demonstrar que essa propriedade é perfeitamente possível, pois não encontra nenhum problema em justificá-la ao aceitar previamente que o ponto de partida de sua análise é a comunidade originária: "esforçar-meei por mostrar de que maneira os homens podem vir a ter uma propriedade em diversas partes daquilo que Deus deu em comum à humanidade, e isso sem nenhum pacto expresso por parte de todos os membros da comunidade". 9

Essa fé programática que expressa Locke é, portanto, coerente com os fins políticos que perseguia os Two Treatises. Porque visa a destruir a argumentação filmeriana, a base de sua teorização afirma a existência de uma comunidade originária. Uma comunidade que Filmer rejeitou, uma vez que vê nela uma fórmula irreconciliável com a propriedade privada ao sustentar que apenas o soberano pode protegê-la como uma concessão de sua vontade absoluta. Como diz Henry Ireton no debate de Putney Church, Filmer dirigiu suas críticas contra os teóricos do direito natural. Para Filmer, os jurisconsultos modernos defendem um modelo que não só reclama a igualdade natural dos homens, mas também, eis o mais grave, o desaparecimento da propriedade ao propor a sua dissolução dentro da comunidade originária. Locke, por isso, tomou cuidado em demonstrar que a sua hipótese inicial é compatível com a propriedade privada, pois se desejava juntar-se aos grupos políticos e religiosos que estavam por trás do partido whig, deveria demonstrá-lo de modo claro e evidente, sem subterfúgios que dissimulassem suas intenções, uma vez que 
do contrário não encontraria neles um apoio à sua política revolucionária. ${ }^{10}$ Como recorda Jeremy Waldron,

o empreendimento de Locke foi, portanto, resolver este dilema e mostrar como a propriedade privada podia surgir legitimamente de um modo natural e sem que a solução fosse incoerente com essas exigências de igualdade e comunidade originárias que exigia como premissa para o seu ataque ao absolutismo régio. ${ }^{11}$

A argumentação lockeana concentrou seus esforços na resolução desse dilema. Por isso a referência que faz àqueles que pensavam ser difícil a justificação natural da propriedade a partir dos pressupostos de uma igualdade e comunidade originárias, e sua declaração incisiva de que essa justificação é possível sem a necessidade de se precisar recorrer a um pacto expresso entre os homens.

A menção que faz Locke àqueles que pensavam ser difícil a justificação da propriedade segundo os pressupostos que ele assume tem como destinatário direto Samuel Pufendorf e Sir Robert Filmer. ${ }^{12}$ As idéias de ambos constituíam sérios obstáculos à teoria que desejava abordar segundo a estratégia política a que serviam os Two Treatises. Na realidade, tanto um como outro baseavam seus respectivos discursos teóricos mediante uma revisão - é o caso de Pufendorf - e uma crítica contundente - conforme a tese de Filmer - das noções que Hugo Grotius havia desenvolvido acerca da propriedade privada. Noções que Locke também tinha presente quando renunciou a demonstração segundo a qual a propriedade podia ser fundada sem a necessidade de um pacto entre os homens. ${ }^{13}$

No De iure belli ac pacis (1625), Hugo Grotius fundamentou a propriedade a partir do que já havia sustentado em 1609 no Mare liberum. ${ }^{14}$ Para Grotius,

10 Cf. ASHCRAFT, 1986, p. 228-285.

11 WALDRON, 1990, p. 149.

12 Cf. OLIVECRONA, 1974, p. 220.

13 Cf. LOCKE, 1998, p. 406.

14 A origem de Mare liberum está na defesa jurídica que a Companhia Holandesa das Índias Orientais confiou a Hugo Grotius em 1604, após a captura por essa companhia de um navio português, o Catalina, em águas do Extremo Oriente. Esse fato provocou uma disputa entre os acionistas da companhia: alguns membros não aceitaram participar dos lucros obtidos com a captura por motivos de consciência. Os resultados das teses de Grotius foi uma que não chegou a ser publicada, e que intitulou De jure praede commentarius. Em 1608 a companhia solicitou a publicação de um de seus capítulos sob o título Mare liberum. Nessa obra, Grotius demonstra que o mar não pode ser objeto de um direito de propriedade privada, tal como Espanha e Portugal reivindicavam a respeito das águas que banhavam as Índias Orientais, conforme o Tratado de Tordesilhas de 1493. Segundo Grotius, nem os espanhóis nem os portugueses podiam excluir os holandeses do acesso aos mares das Índias. Nenhum título jurídico reconhecia um direito sobre eles tal como reivindicavam. O mar deve permanecer aberto ao uso de todos os homens e povos. Primeiro, porque o jus communicationis que ampara a lei natural deixa o caminho aberto aos holandeses. Segundo, por sua própria natureza, o mar não pode ter nenhum dono, pois nada pode possuí-lo e exercer um domínio 
as coisas do mundo haviam sido entregues aos homens em um regime de comunhão indivisível dos bens. Um regime que deixava aberto o conteúdo do mundo ao uso de toda a humanidade, uma vez que por natureza não havia nada que pudesse ser considerada uma propriedade privada: "Um caminho aberto a todos, diz o autor, é o uso comum de todas as coisas." ${ }^{15}$ Essa situação supõe que no estado de natureza cada homem pode tomar à natureza o que desejar para o seu usufruto, fazendo assim, às vezes, um uso particular do direito de propriedade. Mediante a ocupação do necessário para sobreviver, o suum de cada homem se projeta sobre as coisas consumidas. É exatamente isso que Grotius pensa quando escreve sobre a regeneração do mundo após o dilúvio: "Disso cada um podia se apropriar para suas necessidades do que quisesse e consumir o que podia ser consumido. O uso desse direito universal tinha então a função de propriedade, pois do que alguém se havia apropriado outro não podia tirá-lo dele sem injustiça." 16 Uma primeira particularização do mundo teve lugar, pois as coisas consumidas pelos homens não admite nenhum outro uso posterior, transformando-se em substância do ocupante quando, utilizandoas, experimentaram um abuso que as fez degenerar irreversivelmente. ${ }^{17}$

Essa situação, porém, imediatamente foi substituída por outra em que a ambição e o mal impulsionaram os homens a saírem do estado de simplicidade e harmonia no qual viviam desde a expulsão do Paraíso. O emprego do engenho e da astúcia, portanto, induziu os homens a utilizarem mais coisas de que necessitavam para viver na condição primitiva, transformando-se assim na principal causa da separação irremediável e definitiva da comunidade de bens originária:

Os homens não se contentaram mais de se alimentar de frutas silvestres, de habitar em cavernas, de viver nus ou com seus corpos cobertos de cascas de árvores ou de peles de animais selvagens. Passaram a optar por um gênero de vida mais cômodo e tiveram de recorrer à indústria que alguns empregaram para uma coisa e outros para outra. ${ }^{18}$

Desse modo, surgiram as primeiras disputas entre os indivíduos e a necessidade da preservação da paz mediante a institucionalização da

exclusivo sobre ele. A instituição da propriedade privada sobre algo requer uma posse verdadeira e esta só é possível em virtude de sua ocupação. O mar, ao carecer de limites precisos, não pode ser ocupado, de modo que subsiste sobre ele a comunidade originária (communia omnia) que Deus estabeleceu sobre as coisas do mundo após a criação. Cf. TUCK, 1979, p. 60-63; e TULLY, 1980, p. 68-70.

15 GROCIO, 1979, p. 86.

16 GROTIUS, 2004, p. 309.

17 Cf. GROCIO, 1979 , p. 87.

18 GROTIUS, 2004, p. 313-314. 
propriedade privada como um direito; especialmente a partir do momento em que se procedeu também à divisão da terra para atacar a sua exploração. $\mathrm{E}$, devido a sua natureza peculiar, era impossível particularizá-la mediante o simples uso, uma vez que a ocupação não podia transformar a terra em substância do ocupante nem tampouco produzir o abuso que a tornará imprópria no futuro. Foi necessário, por isso, a introdução de um pacto que procedesse à divisão da terra (convenção expressa), ou estabelecesse que "o que cada um ocupasse seria sua propriedade" (acordo tácito). ${ }^{19}$

Graças a esse pacto, Grotius acreditou encontrar a fórmula mais idônea e correta para justificar a propriedade, a saber: a propriedade como um direito inatacável ao ser fundada numa lógica contratual que os homens deviam respeitar porque haviam consentido livre e racionalmente à sua introdução. Contudo, essa solução não resolveu o problema e tampouco foi definitiva, uma vez que estava subordinada a saída do estado de natureza às regras de um pacto que fazia nascer o soberano. Um pacto que ao atribuir um poder absoluto a quem detivesse a soberania poderia ameaçar a estrutura dos direitos de propriedade que haviam sido anteriormente acordados. Se os termos do contrato obrigavam o soberano a respeitar a propriedade dos súditos, na prática a renúncia destes ao poder de resistência deixavam-nos completamente à mercê dos abusos arbitrários do soberano, poder indiscriminado que podia causar danos irreparáveis às propriedades particulares dos subordinados. ${ }^{20}$ Apesar da importância atribuída ao consentimento do povo quando do aparecimento do Estado, o pacto que lhe permitiu nascer era um vínculo tão permanente e indissolúvel que impunha o dever absoluto de obediência, inclusive se fosse contrariado o seu conteúdo. Como assinala Grotius, embora todos os homens têm naturalmente o direito de resistir a uma ofensa, uma vez constituída a sociedade civil com o propósito de defender a paz, surge também um direito superior a nós e às nossas coisas, cuja finalidade é garantir a "tranqüilidade pública". ${ }^{21}$

Foi justamente essa defesa da alienação plena dos indivíduos ao direito de resistência e os perigos da instituição de uma soberania absoluta e indivisível que provocou a desconfiança e converteu a teoria grotiana numa ameaça para teóricos como Locke, que utilizavam a propriedade como um argumento retórico a serviço de uma estratégia política antiabsolutista. Além disso, a

19 GROTIUS, 2004, p. 313-314. Eis a formulação de Grotius: "Foi, no entanto, o resultado de uma convenção, seja expressa através de partilha, seja tácita através, por exemplo, de ocupação".

20 Cf. SCHLATTER, 1951, p. 129-131.

21 GROTIUS, 2004, p.238. 
influência de Grotius já fora sentida através de John Selden e seu De dominio maris jurisbusque ad dominium (1636). Nessa obra, inspirada abertamente em Grotius, Selden tentou demonstrar que, da mesma forma que a terra, o mar havia sido também objeto de divisão privada no estado de natureza, uma vez que estava sujeito a ocupação através da apropriação privada de seus frutos. ${ }^{22}$ À primeira vista, a estrutura de sua argumentação era idêntica à expressada por Grotius, mas é possível perceber numa leitura mais fina que Selden vai mais fundo na "natureza contratual da participação e no caráter independente da vigência do pacto limitador realizado segundo as vigências da lei natural". ${ }^{23}$ Por tudo isso, é lógico que Locke, pensando em Grotius e em seus seguidores ingleses, repete que deseja justificar a propriedade sem a necessidade de um pacto. Como assinala Richard Tuck, Locke estava plenamente consciente dos problemas que continha a teoria da propriedade defendida por Grotius em suas duas obras Mare liberum e De iure belli ac pacis, bem como das perigosas consequiências que encerra seu contratualismo. Quis, por isso, contrapor o seu modelo de propriedade ao dele: deseja demonstrar que é possível justificar naturalmente a propriedade e, ao mesmo tempo, "estabelecer restrições ao governo absoluto". ${ }^{24}$

A teoria da propriedade de Grotius apresentava, porém, outros problemas, como perceberam Samuel Pufendorf e Sir Robert Filmer. Problemas que manifestavam certa falta de idoneidade do mecanismo apresentado pela fórmula contratual no resguardo de sua própria justificação, sobretudo se fosse astutamente interpretada a sua lógica com fins de propaganda. ${ }^{25}$

Em suas Observations Concerning the Originall Government, Sir Robert Filmer criticou os problemas que engendravam as teses de Grotius, especialmente ao evidenciar o absurdo de atribuir ao poder do contrato e sua fórmula a fundamentação da propriedade. Se as coisas do mundo foram ofertadas aos homens em comum, e estes são livres e iguais por natureza,

22 John Selden escreveu seu livro como réplica às teses defendidas por Grotius em Mare liberum, embora se mantivesse dentro dos esquemas racionais de Grotius. Nesse sentido, o livro de Selden - que foi publicado a pedidos de Carlos I - pretendia cumprir dois objetivos: tratar de demonstrar que o mar não era um lugar comum, uma vez que era susceptível de apropriação privada através da aquisição de seus frutos; e justificar assim que a Inglaterra desfrutava de um domínio exclusivo sobre as pescarias que proporcionavam as águas que rodeavam as ilhas britânicas (cf. FLETCHER, 1969, p. 10; e TUCK, 1979, p. 82-100). Devido precisamente a essa polêmica, as idéias de Grotius sobre a propriedade se difundiram amplamente na Inglaterra e ofereceram os contornos a numerosos autores que nelas se inspiraram, como Richard Cumberland (De Legibus Nature, 1672), S. Parker (A Demonstration of the Divine Authority of the Law of Nature, 1681) e G. Towerson (Explication of the Decalogue, 1676), entre outros (cf. SCHLATTER, 1951, p. 131).

23 TUCK, 1979, p. 87.

24 TUCK, 1979, p. 172.

25 Cf. WALDRON, 1990, p. 150-151. 
então o pacto só pode ser obrigatório se for subscrito por todos sem nenhuma exceção. Eis o cerne da crítica de Filmer:

De fato, seria um feito extraordinário se, ao mesmo tempo e no mesmo lugar, todos os homens estivessem de acordo em relação à troca da comunidade natural sobre todas as coisas por um domínio privado. Sem esse consentimento unânime não seria possível modificar a comunidade originária, pois bastaria a manifestação discordante de um só dos envolvidos, e a alteração seria injusta, já que de acordo com a lei natural esse homem discordante teria o direito ao uso comum de todas as coisas do mundo. ${ }^{26}$

Essa crítica de Filmer, no entanto, não é justa com a posição de Grotius, é mesmo imprecisa, pois o autor arminiano jamais defendeu semelhante tese. Como vimos anteriormente, Grotius falou do consentimento, mas de um consentimento que podia ser manifestado expressamente segundo uma divisão pactuada que atribuísse partes aos homens, ou realizado tacitamente mediante a aceitação recíproca do que cada um ocupasse. O autor tampouco escreveu que a manutenção do consentimento deveria ser realizada simultaneamente no tempo e no espaço, já que a lógica do consentimento tácito o desobrigava de tais exigências.

Qual foi, portanto, o motivo que levou Filmer a atribuir a Grotius essa visão da comunidade originária? A explicação é de que ele interpretou mal o jurisconsulto holandês. ${ }^{27}$ Pretendeu atribuir à tese deste último uma herança que não era sua, qual seja, que a tese grotiana conduzia à anarquia hobbesiana e seus pressupostos contratualistas. Como todos são livres e iguais por natureza e recebem um direito comum sobre todas as coisas, então, sustenta Filmer, a comunidade originária é uma espécie de comunismo primitivo capaz apenas de produzir querelas e desordens permanentes. Embora alguns indivíduos particularizassem com seu uso algumas coisas e essa situação fosse tolerada pelos demais, tal circunstância não eliminaria o direito de cada um a reclamála no futuro, pois segue subsistindo a liberdade absoluta. ${ }^{28}$ Embora mediasse a hipótese do pacto, a aliança (foedus) formada teria a força de obrigação permanente para indivíduos ainda livres por natureza? Mais ainda, esse pacto poderia obrigar legitimamente os descendentes que intercederam na sua formação? São essas indagações que motivaram o autor de Kent a dizer o seguinte: "Se nossos pais, ou alguém de nossos antepassados, introduziram voluntariamente a propriedade das coisas e a submissão aos governos, e se 
estava em seu poder introduzi-los ou não, ou tendo-os introduzido, alterar a sua decisão e restaurar seu primeiro estágio de comunidade e liberdade, então que razão pode ser alegada para que neste instante os homens não tenham também esse poder? Portanto, se algum homem disser que reassume seu direito natural à comunidade e proceder na restauração também de sua liberdade natural, e conseqüentemente tomar o que lhe pertence, quem pode dizer que semelhante homem não fez aquilo que corretamente podia fazê-lo? Por isso seria inteiramente lícito a qualquer homem dissolver o governo e destruir a propriedade que assim desejar." 29

Como na crítica anterior, Filmer interpreta com astúcia Grotius, ao atribuir coisas que realmente não escreveu. A atitude de Filmer é simplificadora: quis marcá-lo como um seguidor de Hobbes, cuja defesa do estado de natureza como o âmbito em que os indivíduos têm o direito permanente de usar todas as coisas ao mesmo tempo é fundamental para interpretar a comunidade originária. Direito, portanto, baseado na igualdade e liberdade absolutas que compartilhavam os homens, e que permitia também a revogação do que foi pactuado quando considerassem oportuno para a realização dos seus interesses. ${ }^{30}$ Não obstante, Grotius não pensava desse modo. Admitia que a comunidade originária podia ser modificada por motivos de trocas nas circunstâncias sociais do estado de natureza, pois a ambição humana que movia a apropriação de uma porção de terra não era suficiente para a sua correta particularização. Os homens podiam substituir a ocupação que assumia o papel da propriedade, por um modelo que assegurasse melhor a paz e a harmonia entre eles. É desse modo preciso, porém, que surgiu o pacto que instituiu o direito de propriedade, isto é, um acordo que recebia a sua devida motivação na percepção racional de sua conveniência. ${ }^{31}$

Pouco importa, portanto, que a visão de Grotius não tenha sido aquela apresentada por Filmer. $\mathrm{O}$ caso é que a interpretação desse último tinha um propósito bem definido, qual seja, o de tornar demoníaco o contratualismo, de acordo com sua hipótese de fundo, reduzindo-o à fórmula ameaçadora e repleta de riscos da constituição da propriedade sobre pressupostos jurídicos muito pouco seguros. Se a concessão originária do mundo ofertada por Deus a Adão não constitui um direito de propriedade em favor do primeiro homem, como sustentava Filmer, então a alternativa seria uma comunidade concebida nos termos descritos no Leviathan por Thomas Hobbes, numa situação anárquica 
segundo a qual prosperaria "o direito natural de cada um em relação a todas as coisas", uma condição, portanto, em que não haveria nem propriedade nem domínio, nem a distinção entre teu e meu, mas a plena liberdade e igualdade de todos por todas as coisas, ou seja, aquela condição em que "só pertence a cada um o que ele pode tomar, e só enquanto pode conservá-la". ${ }^{32}$ Assim sendo, a experiência do que havia sucedido em Putney Church torna-se mais clara. A polêmica entre os levellers e Henry Ireton também gira em torno dessa problemática e das implicações políticas que a ela se associam. Como já foi dito, Ireton sustenta a seguinte tese: se em virtude da igualdade e liberdade naturais cada homem pode eleger o seu governante, pela mesma razão ele tem o direito "sobre todas as coisas que vê - comida, bebida, roupa -, para poder adquiri-las e utilizá-las para a sua subsistência". ${ }^{33}$ Para os críticos do contratualismo, porém, o desenlace seria, em qualquer caso, sempre o mesmo: a temível anarquia e, com ela, a vulnerabilidade dos direitos de propriedade que são fundados debilmente segundo uma lógica do contrato.

No De jure naturae et gentium (1672), Samuel Pufendorf persegue e confirma o trabalho de redução terminológica da propriedade à posse privada, tal como havia definido Grotius. Ele identifica dominium e proprietas: "nós consideramos domínio e propriedade como sendo a mesma coisa". ${ }^{34}$ A propriedade é definida como um direito em que a substância de uma coisa pertence ao indivíduo de tal modo que ela não pode pertencer a nenhuma outra pessoa da mesma maneira. Além de confirmar o trabalho de redução terminológica, Pufendorf apresenta também algumas reticências às teses defendidas por Grotius. Em sua obra, o autor alemão defende que a comunidade originária tem um caráter negativo, pois o mundo não pertence na origem a ninguém e está à disposição de todos, isto é, a "comunidade negativa" dos bens não excluía de antemão o uso das coisas contidas no mundo. Assim sendo, cauteloso em fundar na natureza os direitos de convenção, Pufendorf sublinha a existência de um direito natural, no qual correspondem as obrigações humanas, que se aplica ao direito de propriedade nascido do consentimento. Segundo Pufendorf:

O direito do homem sobre as coisas, antes de todo ato humano, não deve ser concebido como um direito exclusivo, mas somente como um direito indeterminado, isto é, que

32 HOBBES, 1996, cap. XVIII.

33 WOODHOUSE, 1986, p. 58.

34 PUFENDORF, 1934, livro IV, cap. IV, § 2, p. 363. 
naturalmente ninguém possui uma porção particular e pode se apoderar de tudo em detrimento dos outros. ${ }^{35}$

Não sendo destinadas a nenhuma pessoa em particular, as coisas do mundo não pertenciam a ninguém e estavam abertas à aquisição de todos como um domínio indefinido; a rigor, considerando o seu status potencial e incerto, nada podia impedir que chegassem a ser possuídas pelos homens. ${ }^{36}$ Para utilizar uma metáfora que melhor explique a tese de Pufendorf, a comunidade originária é muito parecida com um buffet em que a comida está à disposição de todos os comensais, de modo que cada um deles é livre para apanhar o que desejar e na quantidade que achar oportuna, e, assim procedendo, o comensal não está provocando nenhum dano aos demais. ${ }^{37}$

A diferença em relação a Grotius está no fato de Pufendorf acreditar categoricamente que a propriedade só pode ser instituída convencionalmente. Para ele, o direito de propriedade supõe um ato humano, uma convenção que exprime a vocação do homem para dirigir o mundo. ${ }^{38} \mathrm{~A}$ noção de propriedade já é moderna quando a concebe como um direito subjetivo e excludente que se opõe a terceiros; é um direito pleno sobre a substância da coisa e pertence somente a uma única pessoa, não pode ser usufruído por várias simultaneamente. O autor diz: "Ora, da propriedade flui um direito, pelo qual a substância, por assim dizer, de alguma coisa pertence tanto a um que não pode da mesma maneira pertencer totalmente a outro." 39 Por esse motivo, admitir que no estado de natureza havia, ao mesmo tempo, uma comunidade originária de caráter negativo e direito de propriedade de exclusão, significa para Pufendorf um erro lógico inadmissível se não consideramos justamente a presença do pacto prévio. ${ }^{40}$ Por isso, a existência do acordo é fundamental, sem ele não é possível conceber a redução lógica da propriedade enquanto posse privada. Voltando à metáfora do buffet, cada comensal só tem no prato o alimento porque particularizou o seu gesto ao projetar sobre as substâncias ali contidas o suum de sua pessoa, caso contrário, nada garante que os demais permitissem o processo de aquisição sem interferir no seu andamento e resultado, isto é, aceitasse de modo prévio e com uma aceitação tácita o ato de servir-se dos alimentos. É por isso que o autor insiste que a doação de Deus aos

35 PUFENDORF, 1934, livro III, cap. V, § 3, p. 265.

36 Ibidem, livro IV, cap. IV, § 2, p. 363.

37 BUCKLE, 1991, p. 95-97.

38 Segundo Simone Goyard-Fabre (1994, p. 130): “La propriété n'est donc pas de droit naturel, mais d'origine humaine."

39 PUFENDORF, 1934, Liv. IV, cap. IV, § 2, p. 363.

40 TULLY, 1980, p. 72 e TUCK, 1979, p. 156-162. 
homens das coisas do mundo podia ser usada sem caracterizar um domínio, pois os animais assim o faziam, ao consumi-las, sem que as circunstâncias da utilização atribuíssem posse às feras. O domínio pressupõe, portanto, um ato e um acordo tácito ou expresso dos homens:

É preciso notar ainda que a permissão na qual Deus outorgou aos homens o uso dos bens da terra não é a causa imediata da propriedade, enquanto este direito produz efeito sobre o outro; a prova disso é que os animais também se servem das coisas e as consomem com a permissão de Deus, sem que exista entre eles qualquer propriedade. A propriedade supõe necessariamente um ato humano e um acordo tácito ou expresso. ${ }^{41}$

Se os homens têm o poder de amealhar os recursos naturais para a sua sobrevivência, tal como os animais, esse poder, porém, só se converte num verdadeiro direito quando é capaz de criar um efeito moral sobre o resto da humanidade sem causar danos irreparáveis e disputas sem fim. É exatamente isso que o autor diz na seguinte passagem do De jure et gentium:

Um direito capaz de criar um efeito moral sobre o resto da humanidade, de modo que os outros homens não possam usurpar ou concorrer contra as suas vontades, pode surgir apenas por meio de um pacto firmado pelos homens sobre a divisão ou a distribuição dos bens. ${ }^{42}$

Atentem para o final da frase, em que o autor dá ênfase ao pacto como condição do dissídio das altercações e querelas individuais sobre os bens naturais, ao atribuir-lhe um papel mediador sobre a divisão e distribuição dos domínios.

Esse primeiro acordo tácito que consistia no estabelecimento da propriedade privada mediante a ocupação foi seguido de outros mais detalhados e precisos. A comunidade negativa que a lei natural havia estabelecido originariamente extingue-se progressivamente na medida em que a razão orientou os homens para o estabelecimento de sistemas de propriedades mais evoluídos que asseguravam a paz no estado de natureza. ${ }^{43}$ Esses acordos foram nascendo à medida que os pactos prévios se tornaram insuficientes para assegurar a paz que exigia a lei natural. Porquanto o emprego desigual do trabalho na obtenção das coisas necessárias para a sobrevivência dos indivíduos engendrava numerosas

41 PUFENDORF, 1934, livro IV, cap. IV, § 4, p. 365.

42 Ibidem, livro III, cap. V, § 5, p. 265.

43 Ibidem, livro IV, cap. VI-VII, p. 388-407. Nesses capítulos, Pufendorf descreve os diversos métodos que no direito romano eram denominados como "naturais", uma vez concebidos como criações nascidas do acordo comum entre os homens. 
disputas, outras formas negociadas deveriam pautar a estabilização das relações e restabelecer a ordem segura das coisas. Uma vez que a maioria das coisas requer trabalho e cultivo, o homem que não gastou o mínimo de energia necessária para transformá-las em objetos de uso, não poderia reivindicar os mesmos direitos do indivíduo que contribuiu com a sua força de trabalho em torná-las bens consumíveis. Desse modo, as fórmulas contratuais estabelecidas pelos homens deviam aproximar-se paulatinamente do reconhecimento do status de propriedade que melhor se acomodasse a essa realidade, pois a propriedade era antes de tudo uma instituição cujo fim devia facilitar a preservação da paz. Pufendorf, assim, apreciou a importância do trabalho no desempenho do processo de geração do domínio privado, mas não foi capaz de reconhecerlhe também o efeito moral que tornava possível articular uma justificação autônoma da propriedade. ${ }^{44}$ Sua fé no pacto é demasiado forte para deixá-la de lado, uma vez que apenas a vontade pode criar um verdadeiro direito, um poder com efeitos morais que fizesse frente aos outros homens no âmbito do estado de natureza. É como ele próprio reconhece:

Parece que há certa razão que essas coisas devam pertencer a alguns homens mais do que a outros, mas como isso supõe um domínio que excluiria terceiros, então, para que possa surtir plenos efeitos morais, é preciso ao menos ser confirmada por um pacto tácito. ${ }^{45}$

Em suma, há uma razão para que as coisas pertençam a determinadas pessoas e não a outras, razão que Pufendorf atribui, a exemplo de Locke, ao trabalho. No entanto, diferentemente do autor inglês, o seu efeito de exclusão de terceiros exige, para que possa surtir plenos efeitos morais, a confirmação de um pacto entre os envolvidos. Mesmo que seja um pacto tácito.

Locke quem levará a cabo o que Pufendorf apenas esboçou. Partindo do modelo de comunidade originária, o autor inglês descreve os pressupostos de sua teoria sobre a propriedade. É um dever do homem se conservar e, portanto, preservar a sua vida. Essa tese pressupõe que todos os indivíduos racionais são proprietários de sua própria pessoa e, em consequiência disso, do trabalho de suas mãos, da energia gasta no processo de apropriação e transformação dos recursos naturais. Mais exatamente, o fundamento irredutível da propriedade é a propriedade de si mesmo, de sua própria pessoa, e do trabalho que essa pessoa realiza. ${ }^{46}$ Para Manfredo Araújo, "o trabalho é comparável a uma substância 
separável do corpo do indivíduo, que pode ser misturada com o objeto natural trabalhado. Através dessa mistura da substância trabalho, que é propriedade do trabalhador, torna-se também o produto do trabalho propriedade do proprietário do trabalho". ${ }^{47}$ É o trabalho que acrescenta valor às coisas. A propriedade não é a simples afirmação de uma relação do homem com as coisas, ela institui uma transformação que torna possível a passagem do mundo das coisas para o mundo dos bens. Nessa passagem há também o aparecimento do fenômeno do valor: o proprietário de bens é igualmente proprietário de valores. Mas para Locke, não é o ato de propriedade que confere valor às coisas, é simplesmente $o$ ato de posse, posse dos bens. Assim, partindo da atividade que transforma as coisas em bens, alcançamos a origem do valor material. $\mathrm{O}$ trabalho, portanto, inicia o tempo da posse, pois é uma atividade de transformação. Locke deduz a propriedade pelo trabalho. Mas a propriedade não é simplesmente deduzida a partir de uma definição do trabalho como apropriação da natureza, mas a partir de uma caracterização do trabalho como transformação. Transformando a coisa em bem, o trabalho cria um suplemento: o valor. É essa criação de valor, porém, que abre a diferença entre o meu e o teu.

Consciente dos problemas que encerravam os pressupostos de sua teoria, Locke enfrenta a tarefa e defende, antes de assinalar a pretensão de justificar moralmente a propriedade, não precisar recorrer à idéia do pacto para provar o direito fundamental mais importante na vida humana: o direito à autoconservação. E ao fazê-lo, o autor desfere um duro golpe retórico contra Filmer e a seus seguidores tories. Nas palavras de Locke: "Não me contentarei em responder que, se é difícil conceber a propriedade com base na suposição de que Deus deu o mundo a Adão e à sua descendência em comum, é impossível que qualquer homem, a não ser um monarca universal, tenha dado o mundo a Adão e seus herdeiros e sucessores, excluindo-se todo o resto de sua descendência." ${ }^{48}$ Em última instância, a aquisição da propriedade está de acordo com a lei natural e depende inteiramente das obrigações morais do homem.

47 OLIVEIRA, 1993, p. 121. Manfredo Araújo cita oportunamente Gerard Lebrun: "Proprietário de mim mesmo, sou, portanto, proprietário de minhas obras. Eis o 'cogito, ergo sum' do liberal” (LEBRUN, G. As liberdades dentro do liberalismo. In: Passeios ao léu. São Paulo, 1983, p. 44). Duas passagens ilustram bem a tese de Locke, o conhecido parágrafo 27, em que o autor diz: "Embora a Terra e todas as criaturas inferiores sejam comuns a todos os homens, cada homem tem uma propriedade em sua própria pessoa. A esta ninguém tem direito algum além dele mesmo. O trabalho de seu corpo e a obra de suas mãos, pode-se dizer, são propriamente dele. Qualquer coisa que ele então retire do estado com que a natureza a proveu e deixou, mistura-a ele com o seu trabalho e junta-lhe algo que é seu, transformando-a em sua propriedade" (LOCKE, 1998, p. 407-409); e, mais adiante, o início do parágrafo 45, quando Locke defende: "O trabalho, portanto, no princípio, deu um direito de propriedade sempre que qualquer um houve por bem empregá-lo no que era comum" (LOCKE, 1998, p. 424, grifos do autor).

48 LOCKE, 1998, p. 406. 


\section{Referências Bibliográficas}

ASHCRAFT, R. Revolutionary Politics \& Locke's Two Treatises of Government. Princeton: Princeton University Press, 1986.

BUCKLE, S. Natural Law and the Theory of Property. Grotius to Hume. Oxford: Clarendon Press, 1991.

DUNN, J. The Political Thought of John Locke. Cambridge: Cambridge University Press, 1988.

FILMER, R. Patriarcha and Other Political Words of Sir Robert Filmer. Edited by P. Laslett. Oxford: Blackwell, 1949.

FLETCHER, J. John Selden, 1584-1654. London: Selden Society, 1969.

GOYARD-FABRE, S. Pufendorf et le droit naturel. Paris: PUF, 1994.

GROCIO, H. De la libertad de los mares. Tradución de V. de Blanco e L. García Arias. Madrid: Centro de Estúdios Constitucionales, 1979.

GROTIUS, H. O direito da guerra e da paz (De jure belli ac pacis). Tradução de Ciro Mioranza. Ijuí: Editora UNIJUÍ; Fondazione Cassamarca, 2004.

HOBBES, T. Leviathan. Edited by R. Tuck. Cambridge: Cambridge University Press, 1996.

KRAMER. John Locke and the Origins of Private Property. Cambridge: Cambridge University Press, 1997.

LEBRUN, G. Passeios ao léu. São Paulo: Brasiliense, 1983.

LOCKE, J. Dois tratados sobre o governo. Tradução de Julio Fischer. São Paulo: Martins Fontes, 1998.

MACPHERSON, C. B. Democratic Theory: Essays in Retrieval. Oxford: Clarendon Press, 1973.

OLIVECRONA, K. Locke's Theory of Appropriation. The Philosophical Quarterly, n. 24, p. 220-234, 1974.

OLIVEIRA, M. A. de. Ética e sociabilidade. São Paulo: Edições Loyola, 1993.

PUFENDORF, S. De jure naturae et gentium libri octo. Oxford: Clarendon Press; London: Humphrey Milford, 1934. (The Classics of International Law)

SCHLATTER, R. Private Property. The History of an Idea. London: George Allen \& Unwin, 1951.

SUÁREZ, F. Tratado de las leyes y de Dios legislador. Edição bilíngüe de J. R. Eguillor. Madrid: Instituto de Estúdios Políticos, 1967-1968. v. 1.

TUCK, R. Natural Rights Theories: Their Origin and Development. Cambridge: Cambridge University Press, 1979.

TULLY, J. A Discourse on Property: John Locke and his Adversaries. Cambridge: Cambridge University Press, 1980.

WALDRON, J. The Right to Private Property. Oxford: Clarendon Press, 1990.

WOODHOUSE, A. S. P. Puritanism and Liberty: Being the Army Debates (1647-

9) from the Clarke Manuscripts with a Supplementary Documents. London: Dent, 1986. 